\title{
Estudo da viabilidade e da importância do Enoturismo como alternativa de uma atividade sustentável para a região vitivinícola tropical do Vale do Submédio São Francisco (Pernambuco/Bahia, Brasil)
}

\section{Feasibility and importance study of wine tourism as a sustainable alternative activity to the tropical region of São Francisco Submedium Valley (Pernambuco/Bahia, Brazil).}

\author{
Francisco Macêdo de Amorim (AMORIM, F. M. de) ${ }^{*} \mathrm{e}$ \\ Francisco Daniel Carvalho de Medeiros (MEDEIROS, F. D. C. de) ${ }^{* *}$
}

\begin{abstract}
RESUMO - O enoturismo na região vitivinícola tropical do Vale do Submédio São Francisco (Pernambuco/Bahia, Brasil), apesar de ser uma atividade recente, surge como alternativa de renda para diversos setores, se destacando, de maneira especial, pela oportunidade de exploração das particularidades na produção de uvas e vinhos em clima tropical semi-árido. A pesquisa teve o objetivo de identificar a importância do enoturismo para empresas vitivinícolas da região, buscando analisar o retorno social e econômico da atividade. Com base na revisão bibliográfica, foi elaborado um questionário utilizado na coleta de informações e aplicado nos mais diversos setores da cadeia produtiva da vitivinicultura regional. Os resultados obtidos destacaram que o setor tem grande potencial de crescimento e que vem trazendo benefícios para a atividade econômica nas empresas e para o trade turístico das cidades de PetrolinaPE/Juazeiro-BA e circunvizinhas. A falta de incentivos do poder público, a distância entre cidades integradas ao roteiro do vinho, a falta de estrutura nos receptivos de vinícolas e a pouca divulgação foram as principais dificuldades destacadas.
\end{abstract}

Palavras-chave: Enoturismo; Vale do São Francisco; Viticultura Tropical; Semiárido; Sustentável.

ABSTRACT - The wine tourism in the tropical region of Sao Francisco Submedium Valley (Pernambuco/Bahia, Brazil), despite being a new activity, emerges as an alternative for income in many sectors, standing out, specially, for the opportunity of exploring the particularities in grape and wine production in the semiarid tropical climate. The research aimed to identify the importance of wine tourism for local wineries, seeking to analyze the social and economic feedback of the activity. Based on literature review, it was made a questionnaire used to collect data and applied in the most diverse sectors of local wine production supply chain. The results acquired showed that the sector has great potential for growth and has been bringing benefits for the

\footnotetext{
* Formação: Graduação em Agronomia pela Universidade Federal Rural de Pernambuco (UFRPE), Mestrado em Viticultura e Enologia (Instituto Superior de Agronomia - ISA-UTL/ Lisboa, Portugal; Faculdade de Ciências da Universidade do Porto - FCUP/Porto, Portugal; e Estação Vitivinícola Nacional - EVN/Dois Portos, Portugal). Atividade profissional: Professor de Enologia do Instituto Federal de Educação, Ciência e Tecnologia do Sertão Pernambucano (IF Sertão-PE). Endereço físico para correspondência: Rodovia BR 235, Km 22, Projeto Senador Nilo Coelho - N4. CEP: 56.300-000 Petrolina - Pernambuco (Brasil). Fone: +55(87) 2101-8050. E-mail: franciscoamorim@live.com

** Formação: Enólogo (IF Sertão-PE/Petrolina-PE, Brasil). Endereço físico para correspondência: Rodovia BR 235, Km 40, Fazenda Fortaleza I. CEP: 47310-000 - Casa Nova - Bahia (Brasil). Fone: +55 (87) 9912-6311. E-mail: danielcarvalho72@ hotmail.com
} 
companies economic activity and for tourism trade in the cities of Petrolina$\mathrm{PE} / \mathrm{Juazeiro-BA}$ and surroundings. The lack of incentive from public power, the distance among the cities included on the wine route, the lack of structure at the wineries and the little divulgation were the main difficulties highlighted.

Key words: Wine Tourism; São Francisco Valley; Tropical Viticulture; Semiarid; Sustainable Tourism. 


\section{INTRODUÇÃO}

Embora estudos de turismo sejam recentes, se comparados aos de vinhos, pesquisas sobre a relação existente entre vinho e turismo são praticamente inexistentes. O enoturismo, da mesma forma que o turismo, é um agente de mudanças sociais, econômicas ambientais e culturais, o que o torna um fenômeno social complexo (VALDUGA, 2007, p. 12).

Pode-se definir o enoturismo como um segmento do fenômeno turístico, que pressupõe deslocamento de pessoas, motivadas pelas propriedades organolépticas e por todo o contexto da degustação e elaboração de vinhos, bem como a apreciação das tradições, de cultura, da gastronomia, das paisagens e tipicidades das regiões produtoras de uvas e vinhos. É um fenômeno dotado de subjetividade, em que a principal substância que o configura de fato é o encontro com quem produz uvas e vinhos (VALDUGA, 2011, p. 43). Por essa razão, compreende-se que o enoturismo trata-se de um tipo de atividade turística que permite o visitante conhecer a produção de uvas, elaboração de vinhos e outros produtos derivados da uva e do vinho. Essa atividade pode servir de ferramenta para divulgação e integração de empresas e cidades, surgindo como alternativa de renda com agregação de valores para diversos setores econômicos. O enoturismo é na sua essência, de acordo com Getz (1997, p. 2): uma "combinação de cultura, estilos de vida e território".

De acordo com O’Neill \& Charters (2000, p. 113):

[...] apesar do enoturismo ser um segmento relativamente recente, apresenta uma vasta gama de benefícios, incluindo a formação de divisas, a diversificação de atividades, como a geração de atividade econômica secundária, com efeito multiplicador, de maneira que o turismo do vinho torna-se uma indústria muito lucrativa com o capacidade de gerar riqueza e crescimento substancial.

Segundo Inácio (2008, p. 1), o enoturismo "é ainda uma forma capaz de dinamizar o espaço rural". Sendo assim, o enoturismo representa "um veículo para que os turistas visitem uma região, descobrindo, através do vinho, todos os aspectos ambientais, culturais e, consequentemente, gastronômicos de uma região" (GALVÃO, 2006, p. 79). 
O turista do vinho, ou enoturista, pode ser definido como o "sujeito que, a partir de seu desejo de fuga do cotidiano, de nomadismo, de desligamento, deslocou-se de seu local de residência e deseja conhecer algum aspecto relacionado à vitivinicultura" (VALDUGA, 2011, p. 56).

Inácio (2008, p. 5) relata que:

[...] nesta atividade a Europa e o "Novo Mundo" possuem dinâmicas e dimensões distintas. A tradição ancestral de ligação ao vinho, ao pão e ao azeite, culturas tradicionalmente Mediterrânicas, é reconhecida no primeiro caso, contribuindo para o pendor mais tradicional deste setor, onde o enoturismo tem custado mais a afirmar-se. Já no caso dos países que apenas mais recentemente começaram a produzir vinho, ao do Novo Mundo, por assim dizer, este crescimento tem sido galopante e acompanhado pelo desenvolvimento paralelo do enoturismo. É o caso da Austrália, onde esta forma de turismo se revela mais dinâmica e mais suportada tanto institucional como particularmente. Não sendo um país de grandes tradições vitivinícolas, tem sabido crescer e afirmar-se neste universo em termos internacionais. E também o continente em que o fenômeno mais tem sido alvo de reflexões e estudos e tem conhecido desde o início os maiores apoios, tendo estes aparecido quase em simultâneo com o próprio crescimento da atividade vitivinícola. Foi neste contexto que se realizaram os primeiros congressos de enoturismo, que convidavam a uma reflexão sobre o tema e o atiravam para a agenda de muitos dos agentes envolvidos nesta atividade (Primeiro Congresso Australiano de Enoturismo: 1998). O Governo Australiano possui desde 1998 uma "Estratégia Nacional de Enoturismo" que tem largamente contribuído para este desenvolvimento.

Há ainda a referência de que:

[...] os territórios do Novo Mundo apresentam, em termos temporais, uma atividade bastante recente e com pouca tradição vitivinícola, mas com um grau de inovação considerável nas modalidades encontradas para o desenvolvimento da atividade enoturística associada ao vinho e à vinha, que lhes possibilitam um volume de turismo interno e internacional francamente significativo. Nestes locais o desenvolvimento do conceito de "Destino Enoturístico" assenta numa miríade de hipóteses de atividades possíveis reforçando as suas vocações turísticas. Muitas das propriedades existentes vivem quase tanto do Turismo, ou mais, do que da produção vinícola que se encontra subjacente a este negócio (INÁCIO, 2008, p. 5).

No Brasil esse segmento turístico se destaca como forma de aproximar culturas e despertar o conhecimento e consumo de vinhos, já que os visitantes passam a entender melhor como funciona a vitivinicultura. Além disso, pode despertar interesse das empresas que participam direta ou indiretamente desse segmento, pois surge a oportunidade de apresentar seus produtos e tornar conhecida sua marca. 
A região do Vale do Submédio São Francisco, localizado no Nordeste do Brasil, na zona intertropical que fica entre os estados de Pernambuco e Bahia, possui fatores naturais que são muito diferenciados quando comparados com a grande maioria das tradicionais regiões produtoras de uvas e vinhos (TONIETTO, 2007, p. 41).

Segundo Tonietto e Carbonneau (1999, p. 93):

[...] a viticultura desenvolvida no Vale do Submédio São Francisco possui características climáticas que a distingue do restante das regiões de viticultura tradicional de vinho em todo o mundo. A região está situada em zona de clima tropical semi-árido, entre $09^{\circ}$ e $10^{\circ}$ de latitude Sul. Nela, a produção de uvas pode ser escalonada ao longo dos diferentes meses do ano. A disponibilidade heliotérmica nessas condições permite o desenvolvimento vegetativo contínuo da videira durante todo o ano, possibilitando a obtenção de mais de uma colheita por ano.

Essa condição diferenciada pode ser um grande contributo à alternativa do desenvolvimento de uma atividade enoturística mais robusta, pela liberdade de oportunizar ao turista o conhecimento de todas as atividades vitivinícolas em qualquer época do ano.

Apesar de o enoturismo ter surgido nessa região há pouco tempo, é comprovado o aumento significativo do fluxo de visitantes a cada ano que se passa. Tentando aprofundar o conhecimento e disponibilizar informações sobre o assunto, essa pesquisa veio investigar a importância do enoturismo para as empresas vitivinícolas dessa região e sua interferência na busca pelo desenvolvimento sustentável.

\section{DESENVOLVIMENTO DO TEMA}

A pesquisa teve caráter quantitativo-descritivo e a metodologia utilizada foi a de pesquisa de campo, escolhida por permitir maior aproximação da realidade, em função da consulta in loco, com personagens inseridos no contexto da atividade.

As revisões bibliográficas possibilitaram um aprimoramento do embasamento teórico sobre o tema e foram essenciais para a formatação dos questionários aplicados. As avaliações contemplaram representantes de todas as empresas vitivinícolas da região atualmente em atividade, que responderam aos questionários de acordo com uma visão do empresário em relação à atividade e suas implicações comerciais. Também foram 
consultados aqueles que podem ser considerados como sendo os principais personagens do negócio, denominados enoturistas, que participam ativamente de todo o processo, sobretudo orientando os ramos da atividade de acordo com as suas especificidades. Nesse processo, participaram ainda da análise alguns representantes do poder público e empresários de outros setores envolvidos na cadeia do enoturismo regional.

Através do recolhimento de dados via aplicação dos questionários, com posterior processamento e interpretação dos resultados, foi possível obter informações importantes sobre a viabilidade dos investimentos realizados nos diversos setores da cadeia enoturística. A pesquisa realizada permitiu compreender melhor o perfil do consumidor que visita a região, os problemas que dificultam o crescimento do setor enoturístico regional e as possíveis soluções de melhoria e impulso para o avanço desse segmento de negócio.

As consultas bibliográficas realizadas concomitantemente ao período da pesquisa orientaram plenamente o rumo do trabalho científico, à medida que possibilitaram descrever situações específicas da região, permitindo caracterizar e entender que algumas ocasiões necessitam de cuidados especiais na análise e interpretação dos resultados gerados.

Questionários destinados à análise do setor produtivo da uva e do vinho, no que compete à preocupação com resultados econômicos essencialmente, foram cuidadosamente preparados sem aprofundamento no conteúdo financeiro, restringindose à busca de informações que comprovassem a visibilidade técnica da implementação de um roteiro específico voltado para o enoturismo na própria empresa. Junto a essa análise foram ainda consultadas as expectativas dos empresários quanto à expansão da atividade no âmbito de empresa.

Quanto aos enoturistas, como análise geral, face ao panorama atual, sentiu-se a necessidade de caracterizar o perfil desse público, permitindo gerar dados que comprovaram a necessidade de realizar adaptações, a serem adotadas como estratégias para o sucesso da atividade. Essas adaptações surgem mediante atendimentos específicos às demandas que cada faixa etária, nível de formação e padrão socioeconômico exige.

O poder público também tem o seu importante papel nesse contexto, na medida em que os seus responsáveis reconheçam suas atribuições específicas e que, através de 
medidas parlamentares em prol de uma legislação favorável ao setor e a disponibilização de determinados recursos para aplicações específicas, justificam sua importância.

De maneira geral, foram abordados assuntos referentes à importância do setor enoturístico, às dificuldades enfrentadas, perspectivas futuras e melhorias que se deve estabelecer para ampliar o número de visitantes e o interesse pelo enoturismo da região em foco.

\section{RESULTADOS E DISCUSSÕES}

O resultado da pesquisa mostrou evidências de que o enoturismo representa um grande impulso para o crescimento da vitivinicultura regional, pois cria um leque de oportunidades não apenas para um único setor econômico, mas para o desenvolvimento sustentável de cidades e empresas envolvidas. Os representantes das empresas que foram entrevistados, no geral, demonstraram que as vendas já haviam aumentado de forma razoável, tendo forte influência desse segmento de negócio, gerando emprego e renda para a população. Todos os representantes das empresas questionados afirmaram que essa é uma ferramenta de grande importância para o sucesso do setor vitivinícola.

Referente ao motivo que leva os proprietários de uma empresa a abrir as portas para visitações de grupos turísticos foi observado que a divulgação da marca, aumento dos lucros e satisfação da clientela foram os principais fatores que despertaram interesse (Figura 1). Com base nas respostas concluiu-se que quando os consumidores visualizam o processo de elaboração e entram em contato direto com os produtores, passam a ter uma visão diferenciada do local, das pessoas, do sistema de produção e da qualidade dos produtos, quebrando paradigmas contraditórios que prejudicariam as vendas. 
FIGURA 1 - MOTIVO QUE LEVA UM EMPRESÁRIO DO SETOR VITIVINÍCOLA A INVESTIR NO ENOTURISMO DO VALE DO SUBMÉDIO SÃO FRANCISCO.

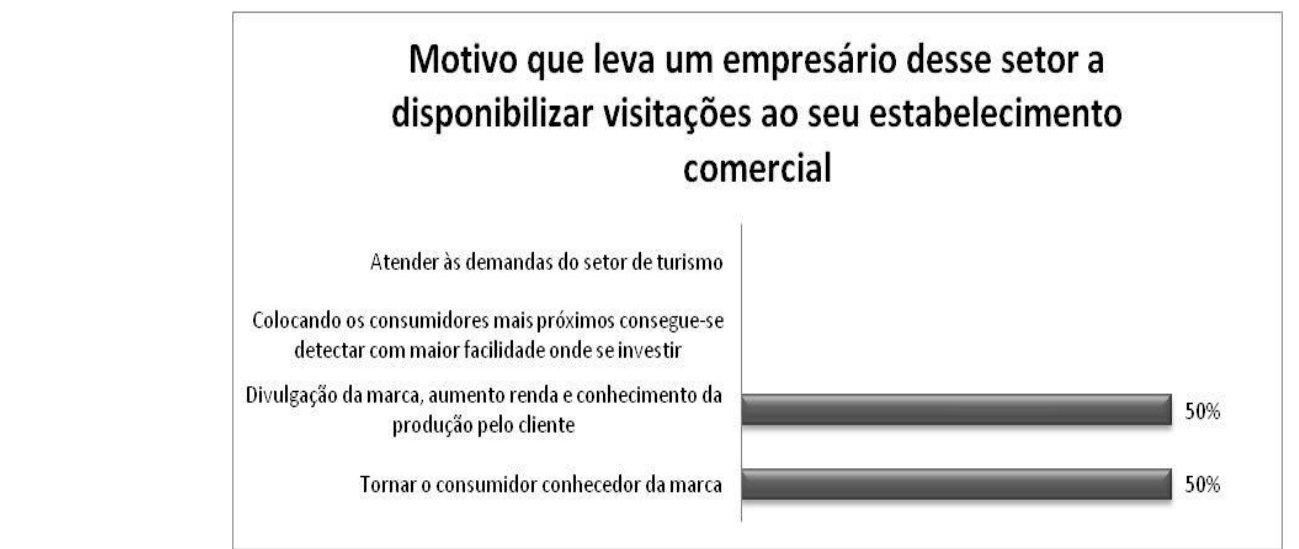

Fonte: Pesquisa de campo, 2013.

Tratando-se dos serviços oferecidos aos enoturistas na região do Vale do São Francisco, foi observado que a maioria dos entrevistados deu a entender que a região ainda precisava de algumas modificações em diferentes setores, conforme mostrado na figura 2.

FIGURA 2 - ÍNDICE DE SATISFAÇÃO DAS NECESSIDADES E DESEJOS DOS ENOTURISTAS EM RELAÇÃO AOS SERVIÇOS OFERECIDOS NA REGIÃO DO VALE DO SÃO FRANCISCO.

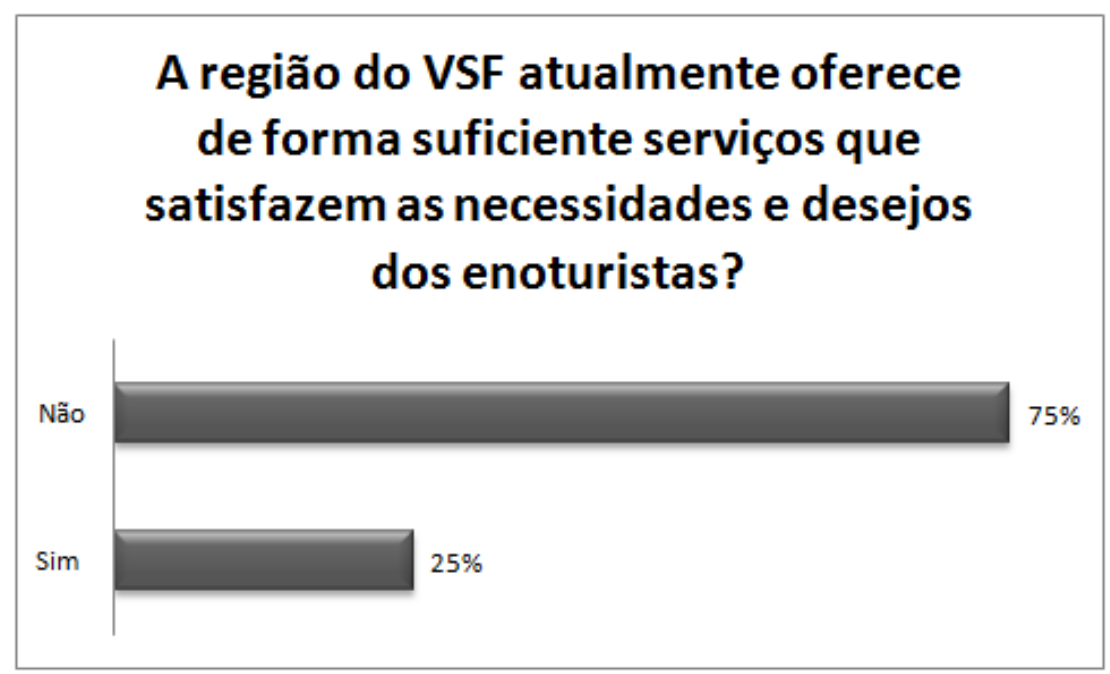

Fonte: Pesquisa de campo, 2013.

Entre as melhorias recomendadas pelos entrevistados estão: melhoria da rede hoteleira e transporte; maior investimento de algumas empresas; apoio do governo; disponibilização de serviços e mão de obra qualificada; disponibilização de profissionais do segmento de guia de turismo com informações suficientes que possam 
dar suporte ao roteiro enoturístico do Vale do Submédio São Francisco; melhorar o setor de saúde, educação e segurança; criação de alusões que informem às pessoas sobre o potencial regional de produção de uva e elaboração de produtos derivados da uva e do vinho; criar opções que permitam o enoturista visitar todas as vitivinícolas da região e; sinalização adequada das principais rotas de turismo local.

Baseando-se nos trabalhos apresentados por Costa e Kastenholz (2009) ${ }^{1}$, Losso (2010), Getz e Brown (2006) $)^{2}$ e Simões (2008) ${ }^{3}$, apud PANCERI (2012, p. 15):

[...] verifica-se que uma rota enoturística uma rota de vinhos deve ser constituída em uma ou mais regiões produtoras de uva e vinho, que disponibilize de infra-estrutura básica para a prática do turismo, sendo devidamente sinalizada e organizada, abrangendo espaços e equipamentos de uso turístico cuja oferta inclua a apreciação de vinhos, centros de interesse de vitivinícolas, museus e/ou espaços dedicados a cultura, e empreendimentos atrelados a gastronomia, que sejam capazes de gerar um real interesse turístico.

Outra vantagem do enoturismo é o seu poder de familiarização com o tema. Pois o enoturismo favorece tanto ao enófilo dedicado como a uma pessoa que nunca tenha tido contato com as "delícias de Baco". O que faz do enoturista um "conhecedor ocasional.

Compreende-se que o Vale do São Francisco é uma região muito recente na produção de uvas, elaboração de vinhos e derivados da uva e do vinho, com empresas ainda em fase de adaptação para receber visitação turística. Nesse contexto, entende-se que seja de fundamental importância a união de forças que busquem as melhorias necessárias para o crescimento do setor. A maior parte dos entrevistados evidenciou que os serviços oferecidos na região não satisfaziam as necessidades e os desejos dos enoturistas que desejassem explorar a atividade do enoturismo.

A rota enoturística demarcada na região do Vale do São Francisco ainda não conseguiu integrar todas as empresas de produção vitivinícola existentes, pelo fato

\footnotetext{
${ }^{1}$ COSTA, A., KASTENHOLZ, E. O enoturismo como fator de desenvolvimento das regiões mais desfavorecidas. CONGRESSO DE DESENVOLVIMENTO REGIONAL DE CABO VERDE, Anais..., 2009, p. 1489 - 1508.

${ }^{2}$ GETZ, D., BROWN, G. Benchmarking wine tourism development - The case of the Okanagan Valley, British Columbia, Canadá. Internacional Journal of Wine Marketing, 2006, v. 18 (2), p. 78-97.

${ }^{3}$ SIMÕES, O. Enoturismo em Portugal: as Rotas de Vinho. In: Pasos-Revista de Turismo y Patrimonio Cultural, 2008. v. 6, n 2: p. 269-279.
} 
especial da distância entre elas. Mais danoso ainda para o progresso dessa atividade são alguns fatores que, se existissem, seriam perfeitamente indutores ao perfeito funcionamento de negócio. Dentre esses fatores, é possível destacar a dificuldade de hospedagem nas cidades incluídas no roteiro e a qualidade no fornecimento de refeições adequadas. O roteiro enoturístico implantado contempla principalmente os municípios de Casa Nova (do lado baiano) e Santa Maria da Boa Vista e Lagoa Grande (do lado pernambucano) (FLORES, 2012, p. 109). Contudo, considera-se que outras cidades como Juazeiro, Sobradinho e Curaçá, na Bahia, Petrolina, Orocó, Cabrobó e Belém do São Francisco, em Pernambuco, possuem importantes contributos a serem integrados ao roteiro do vinho do Vale do São Francisco.

Durante as entrevistas, foi possível perceber o interesse pelo investimento no enoturismo local, devido à potencialidade e à diferenciação da região. Essa diferença se deve fundamentalmente pela particularidade climática. É clara a crença na expansão da rota enoturística. No entanto, foi possível perceber que alguns empresários demonstraram temor em efetuar grandes investimentos, tendo em vista que a falta de incentivos por parte do governo federal e estadual, contribuindo com as suas obrigações específicas é realidade marcante. Atrelado a isso, há ainda o fato de que, embora a perspectiva de crescimento seja grande, há necessidade de maior segurança na ampliação do número de visitantes, o que poderia justificar a viabilidade de aportes financeiros grandiosos para enriquecimento da proposta de evolução do setor.

Observando a importância do enoturista para o crescimento do enoturismo no Vale do Submédio São Francisco, a pesquisa traçou também o perfil dos enoturistas que se interessavam por apreciar as exclusividades que a região oferece.

Nessa parte da pesquisa, foram selecionadas aleatoriamente 100 pessoas, que foram entrevistadas entre os meses de março e abril de 2013. No questionário se relacionavam características dos visitantes e motivos que os levavam a visitar a região. Vale ressaltar que a maioria dos entrevistados esteve participando da Feira Nacional da Agricultura Irrigada - FENAGRI 2014 e, portanto, foram na sua grande maioria classificados como turistas, que em função do evento estavam pela região.

Os resultados obtidos mostraram que a maioria dos visitantes era oriunda da região nordeste do Brasil ( $86 \%$ dos entrevistados), principalmente do estado de Pernambuco (figura 3). O que foi considerado instigante é a pouca quantidade de 
pessoas da região do Vale do São Francisco, pois os $10 \%$ dos entrevistados que representaram a região, na sua maioria eram pessoas que estavam trabalhando direta ou indiretamente com o enoturismo local, permitindo afirmar que muitos moradores ainda não conheciam a potencialidade do enoturismo da região.

FIGURA 3 - REGIÃO DE ORIGEM DOS ENTREVISTADOS.

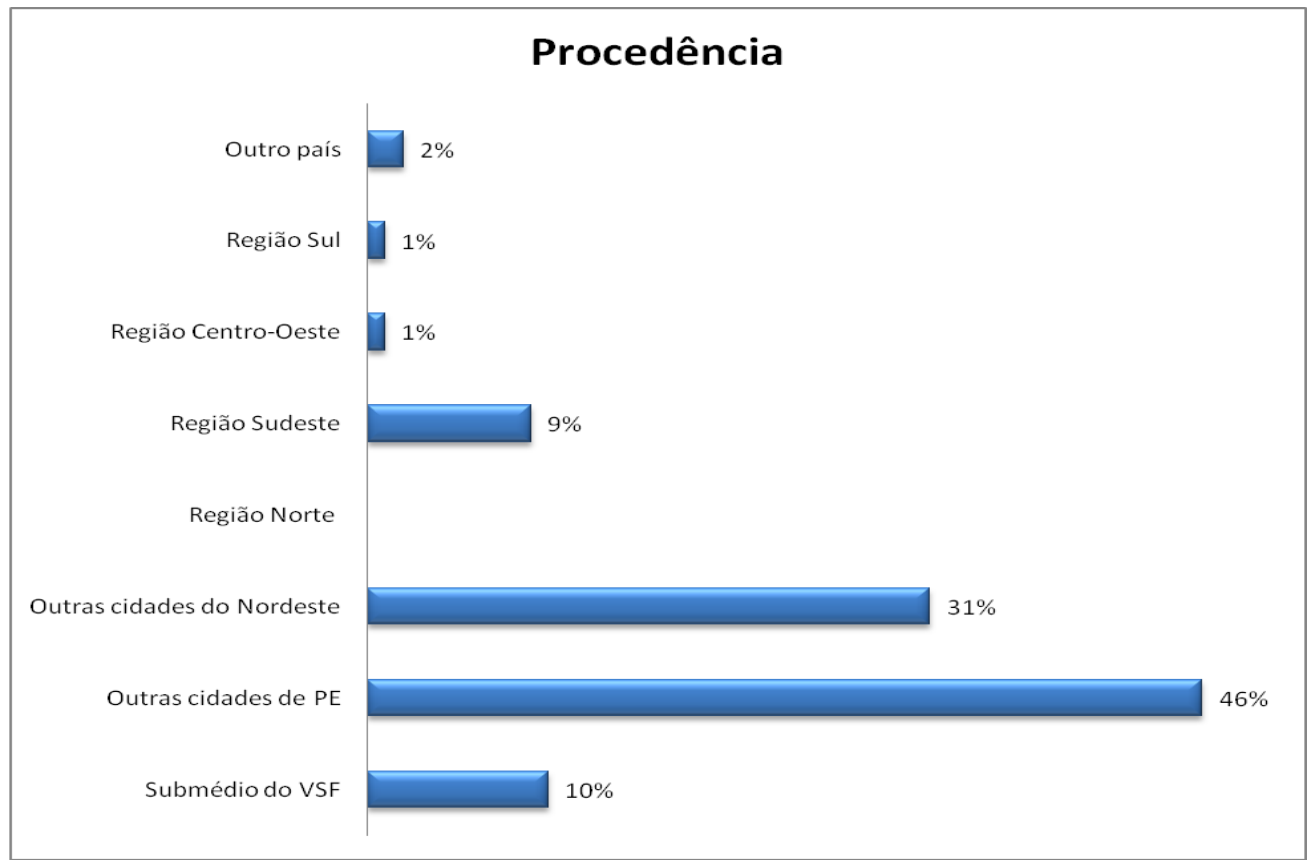

Fonte: Pesquisa de campo, 2013.

No que se refere à escolaridade, na figura 4 se mostra que a maioria dos entrevistados possuía ensino superior incompleto (30\%), curso superior completo (26\%) ou pós-graduação $(22 \%)$, permitindo identificar o alto nível de conhecimento dos enoturistas e a necessidade de qualificar profissionais que proporcionem um atendimento satisfatório ao cliente. 
FIGURA 4 - NÍVEL DE ESCOLARIDADE DOS ENOTURISTAS QUE VISITAM O VALE DO SÃO FRANCISCO.

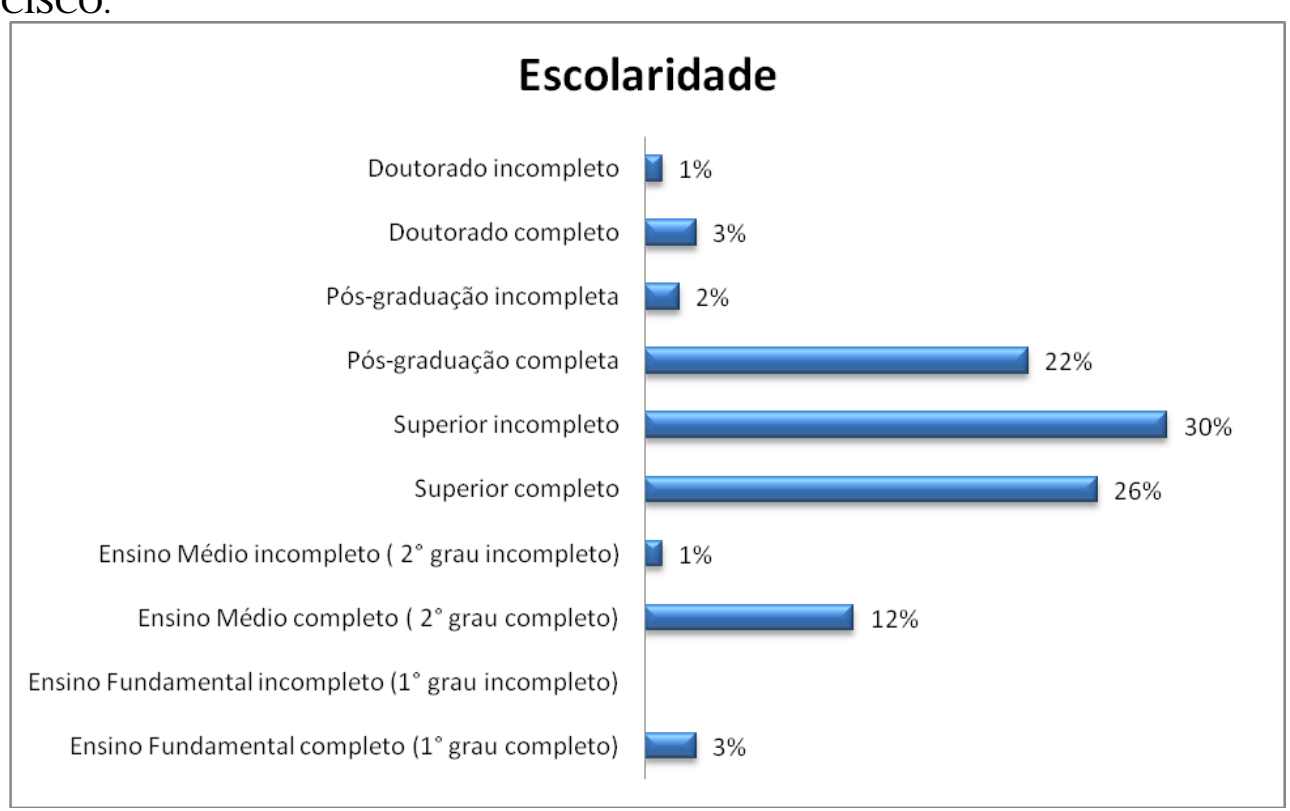

Fonte: Pesquisa de campo, 2013.

Verificou-se também que as mulheres têm se apresentado como grandes apreciadoras do glamour do vinho, aumentando essa fatia de participação, com $56 \%$ do total de entrevistados (figura 5), especialmente quando comparado com dados de Zanini (2007, p. 84), quando mostrou em pesquisa realizada que os homens correspondiam a $67 \%$ do total de visitantes.

FIGURA 5 - GÊNERO DOS ENOTURISTAS ENTREVISTADOS.

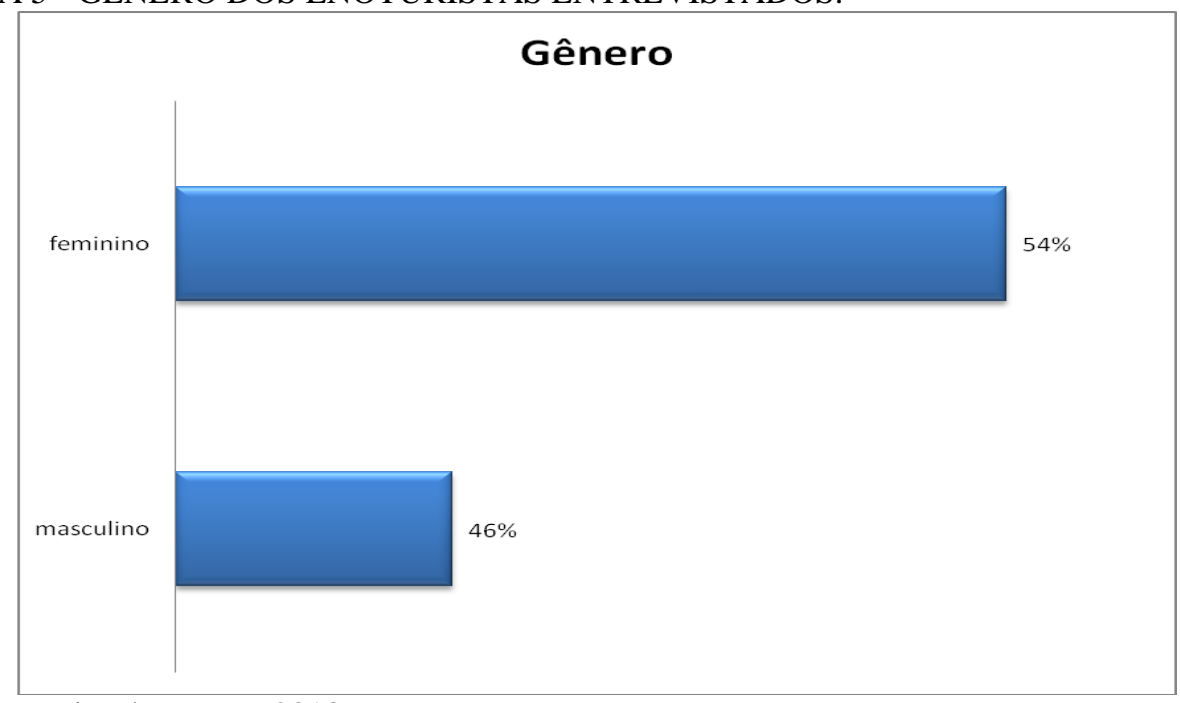

Fonte: Pesquisa de campo, 2013. 
Quanto à faixa etária, a grande maioria dos enoturistas (62\% dos entrevistados) esteve na média até 40 anos, como pode ser visto na figura 6.

FIGURA 6 - IDADE MÉDIA DOS ENTREVISTADOS.

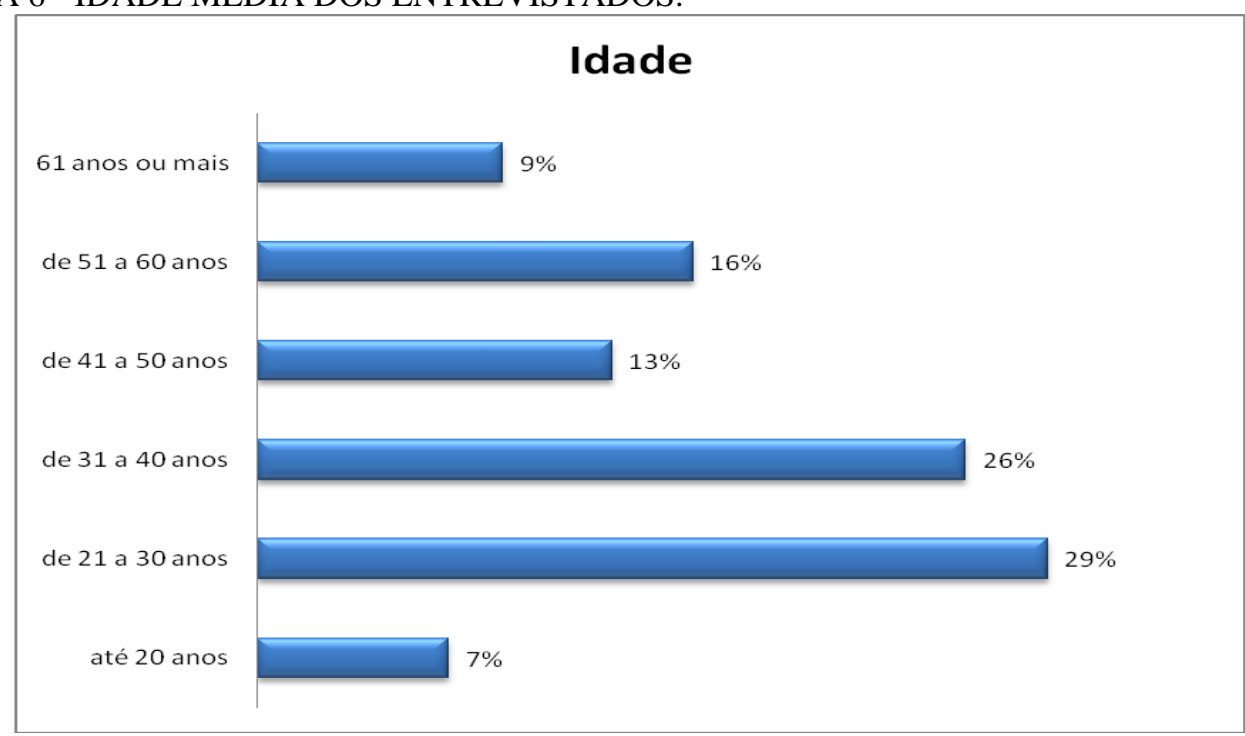

Fonte: Pesquisa de campo, 2013.

A maioria dos visitantes, em participação percentual de $38 \%$ manifestou viajar em excursão com grupos (figura 7), permitindo considerar que realmente o enoturismo dessa região tem potencialidade, pois esse resultado mostra o interesse de grupos em conhecer as particularidades regionais.

É perceptível também o aumento de visitantes que vão acompanhados com amigos, família ou cônjuge (figura 7). Esses representaram um total de 57\%. Pesquisas realizadas anteriormente por Zanini (2007, p. 85) mostraram que antes esse resultado se resumia em 29,32\% dos entrevistados. Essa diferença pode ser justificada pela maior disponibilização de atrativos turísticos atualmente na região, quando comparados ao passado. 
FIGURA 7 - COM QUEM ESTÃO VIAJANDO OS ENOTURISTAS.

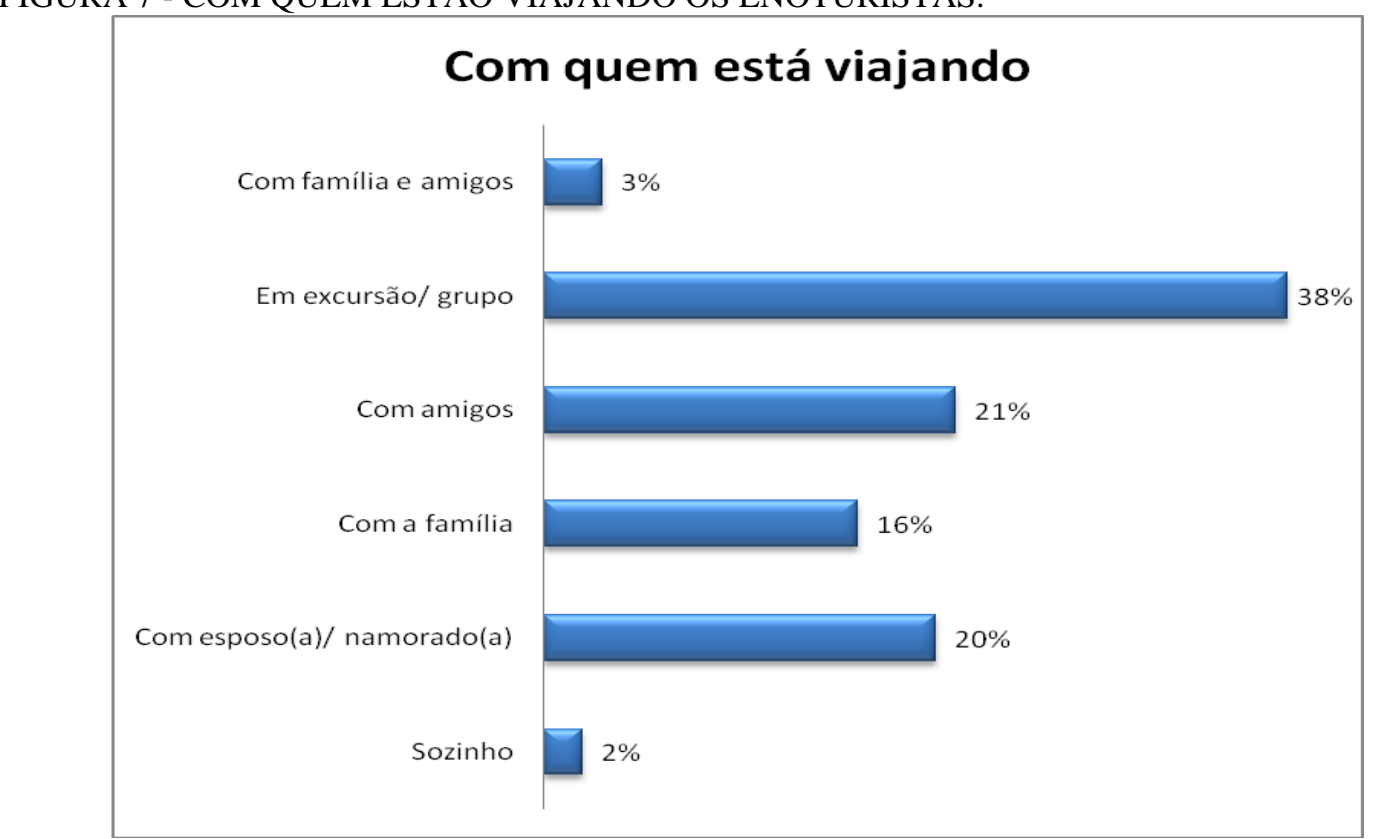

Fonte: Pesquisa de campo, 2013.

Na figura 8 que segue, se indica o grau de interesse atribuído a cada um dos possíveis motivos que leva um turista a visitar a região do Vale do Submédio São Francisco. 
FIGURA 8 - DIFERENTES NÍVEIS DE INTERESSE DOS TURISTAS QUE VISITAM A REGIÃO DO SUBMÉDIO VALE DO SÃO FRANCISCO.

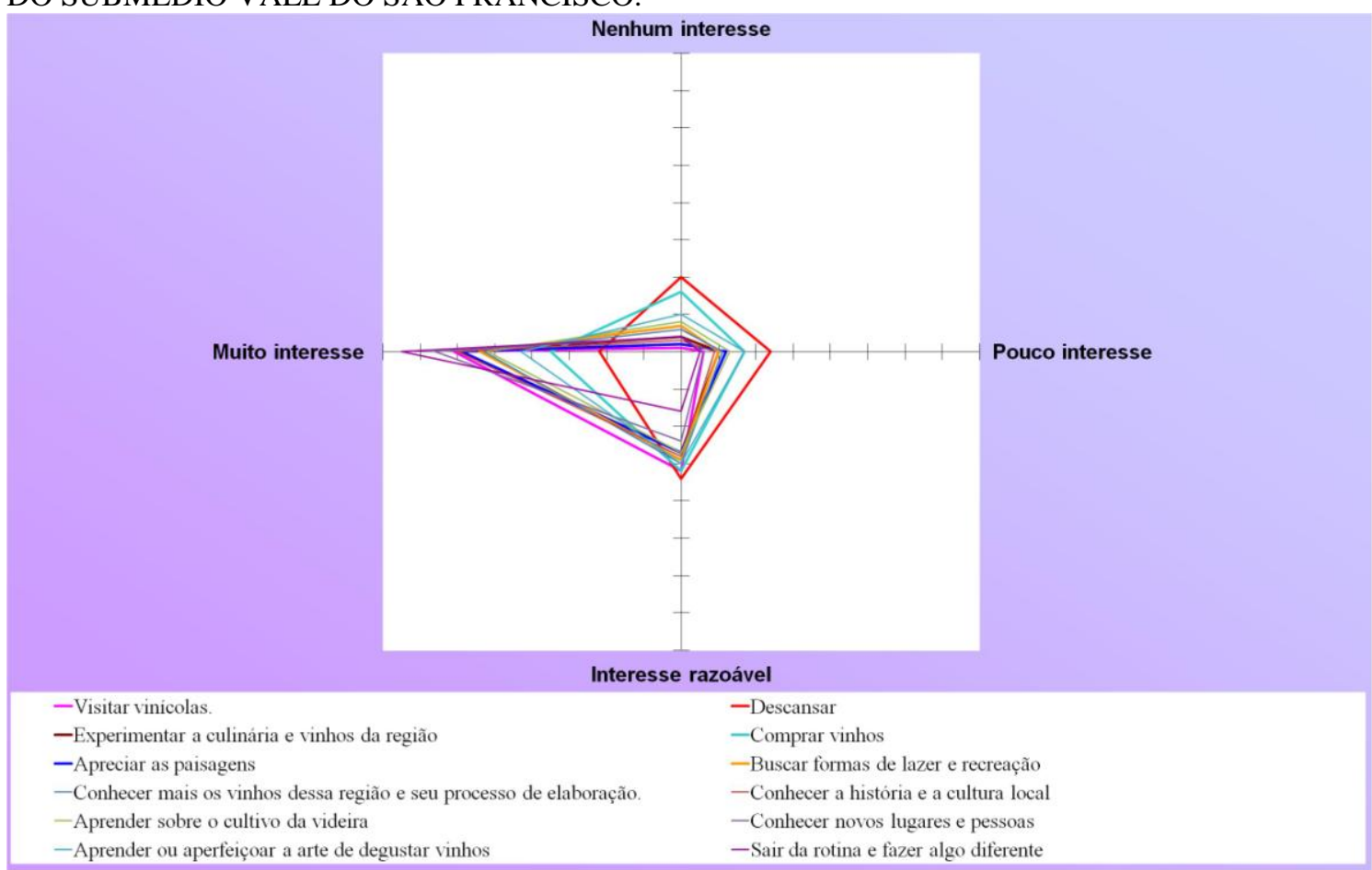

Fonte: Pesquisa de campo, 2013.

Considera-se ter ficado bastante perceptível o interesse dos turistas em apreciar “o novo" e fazer algo diferente. Isso permite dizer que é necessário disponibilizar maior quantidade de opções para entretenimento e variedades gastronômicas especializadas, visando incremento na quantidade de visitas. É ainda necessário que sejam realizados investimentos em atividades culturais locais diversificadas, mediante informação explícita de que $88 \%$ dos visitantes mostraram ter muito ou razoável interesse em conhecer a história e a cultura local, enquanto apenas $12 \%$ apontaram pouco ou nenhum interesse.

Com os resultados apresentados na última figura 8 verificou-se ser evidente o interesse dos visitantes em aprender sobre o cultivo da videira, conhecer os vinhos e seu processo de elaboração. Como consequência das informações mais concisas obtidas sobre vinhos durante os períodos de contato com as ferramentas integrantes da atividade enoturísticas, os enoturistas acabam por comprar produtos que muitas vezes superavam suas expectativas.

As diversidades de cultura, culinária e paisagens específicas da caatinga e das margens do rio São Francisco, constituem também um particular diferencial, que 
agregam um grande valor às atividades que poderão ser inseridas no roteiro do enoturismo.

Através dos resultados obtidos, pode-se afirmar com convicção que o enoturismo chega como uma ferramenta que favorece efetivamente a quebra de paradigmas benéficos ao desenvolvimento da atividade na região do Vale do Submédio São Francisco. O contato do consumidor com um apreciador/divulgador que enaltece a qualidade dos produtos e serviços regionais de maneira segura e positiva pode favorecer uma melhor aceitação de um produto, superando qualquer possibilidade de discriminação ou preconceito.

Com as entrevistas realizadas com representantes do poder público e empresários de outros setores ligados ao enoturismo, pode-se aferir que a crença na potencialidade do segmento existe. Porém os governos federal e estadual não estavam favorecendo o crescimento, em função da falta de investimento que são itens de sua responsabilidade, tais como: pavimentação, sinalização das estradas, melhoria dos setores de saúde e educação, e redução na arrecadação de impostos.

Questionando-se sobre o que poderia ser feito em busca da expansão do enoturismo na região do Vale do São Francisco, percebeu-se a clareza que apontou para maior integração entre as empresas do setor, viabilizando esse desenvolvimento, conforme apresentado na figura 9 a seguir.

FIGURA 9 - O QUE PODE SER FEITO PARA EXPANDIR O ENOTURISMO NA REGIÃO DO SUBMÉDIO VALE DO SÃO FRANCISCO.

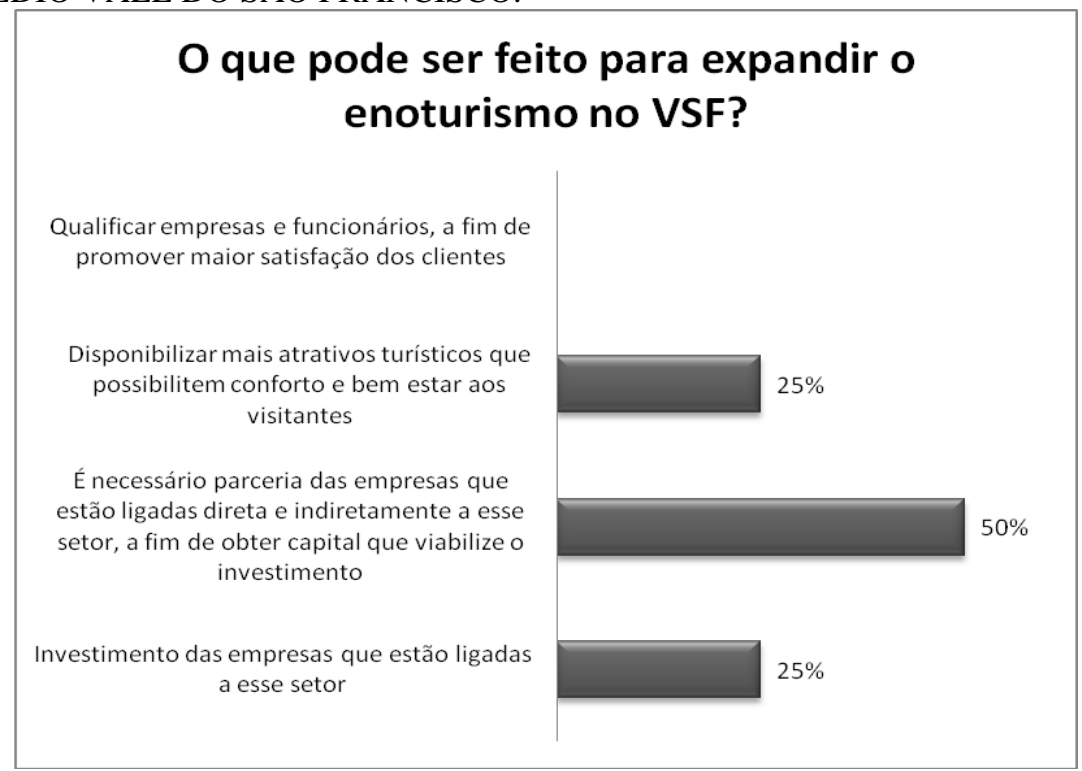

FONTE: Pesquisa de campo, 2013. 
Grande parte dos entrevistados evidenciou que o governo estava olhando de maneira desatenta para o segmento, passando despercebida a ideia de que essa poderia ser uma forma de obter o desenvolvimento sustentável, oferecendo diversas condições para melhoria de vida da população. Os representantes do governo entrevistados argumentaram que faltava aos representantes do segmento criar projetos que contivessem demandas específicas voltadas para o atendimento das necessidades gerais. Conforme relatado por Dias e Vital (2012, p. 660):

[...] o enoturismo corresponde a um segmento turístico não massivo que, quando bem planejado e colocado em execução, constitui um instrumento de transformação sócio-político-econômica do lugar, trazendo como perspectiva um desenvolvimento local e regional que é, hoje, percebida pelas propriedades vitivinicultoras como uma importante ferramenta na divulgação de suas marcas e na ampliação de seus faturamentos.

Nesse sentido, há justificativa clara de potenciais realidades sobre o desenvolvimento da atividade na região pesquisada, porém com reais evidências de que grandes ajustes necessitam ser realizados, para que seja possível uma efetiva formatação do segmento como alternativa viável de exploração.

\section{CONSIDERAÇÕES FINAIS}

Considera-se ser totalmente evidente destacar a importância do enoturismo para o desenvolvimento não apenas das empresas vitivinícolas, como também de diferentes setores que movimentam a economia da região, já que esse segmento turístico chega a beneficiar diferentes segmentos de mercado, quer sejam interligados diretamente ou indiretamente.

O enoturismo da região do Vale do Submédio São Francisco está em crescente expansão, necessitando de total atenção e dedicação por parte dos empresários. Assim como também é preciso que os governos federal, estadual e municipal criem formas de beneficiar o setor com investimentos que possam atender algumas das principais dificuldades enfrentadas atualmente. 
Sem dúvida essa atividade é percebida pelos proprietários das propriedades vitivinicultoras como uma importante ferramenta na divulgação de suas marcas e na ampliação de seus faturamentos.

É necessária ainda, a união de forças entre cidades e empresas, visando aumentar a satisfação dos visitantes e tornar a população ciente da potencialidade local.

Atualmente pode se acreditar que essa pode ser uma ferramenta que permitirá futuramente a obtenção do desenvolvimento sustentável da região caso sejam feitos investimentos e adequações necessárias.

\section{REFERÊNCIAS}

DIAS, P. P.; VITAL, T. W. O Desenvolvimento do Enoturismo no Vale do São Francisco: um segmento em expansão. Turismo em Análise, São Paulo, v. 23, n. 3, p. 643-662, dez. 2012.

FLORES, M. A. D.; FLORES, A. Diagnóstico do enoturismo brasileiro: um mercado de oportunidades. Brasília, DF: SEBRAE; Bento Gonçalves, RS: IBRAVIN. 126 p., 2012.

GALVÃO, P. Enoturismo e dinâmica sócio-espacial no Vale do São Francisco (PE). 2006. Dissertação (Mestrado em Geografia) - Universidade Federal de Pernambuco, Recife, 2006.

GETZ, D. Event Management \& Event Tourism. New York: Cognizant Communication Corporation, 1997.

GETZ, D.; BROWN, G. Benchmarking wine tourism development: The case of the Okanagan Valley. Internacional Journal of Wine Marketing, British Columbia, Canada, v. 18 (2), 2006, p. 78-97.

INÁCIO, A. I. O Enoturismo: da tradição à inovação, uma forma de desenvolvimento rural. CONGRESSO DE ESTUDOS RURAIS, 3, 2007, Faro, Portugal. Actas... Universidade do Algarve: SPER / UAlg, 2008, CD-ROM.

O'NEILL, M.; CHARTERS, S. Service quality at the cellar door: Implications for Western Australia's developing wine tourism industry. Managing Service Quality. 10 (2). p. 112. 2000.

PANCERI, C. P. Enoturismo de altitude de Santa Catarina: um estudo buscando identificar os atributos competitivos das empresas vinícolas. 2012. 30 p. TCC 
(Especialista em administração estratégica e financeira). Videira, SC: Universidade do Oeste de Santa Catarina, 2012.

TONIETTO, J. Les macroclimats viticoles mondiaux et l'influence du mésoclimat sur la typicité de la Syrah et du Muscat de Hambourg dans le sud de la France: méthodologie de caractérisation. 1999. 233 f. Tese (Doutorado em Agronomia) - École Nationale Supérieure de Agronomie, Montpellier, 1999.

TONIETTO, J. TEIXEIRA, A. H. de C. O clima vitícola do submédio São Francisco e o zoneamento dos períodos de produção de uvas para elaboração de vinhos. In: I WORKSHOP INTERNACIONAL DE PESQUISA. A Produção de Vinhos em Regiões Tropicais, 2007. p. 41-51.

VALDUGA, V. O processo de desenvolvimento do enoturismo no Vale dos Vinhedos. 2007. 148 p. Dissertação (Mestrado em Turismo). Caxias do Sul, RS: Universidade de Caxias do Sul, 2007.

VALDUGA, V. Enoturismo no Vale dos Vinhedos. Jaguarão, RS: Fundação Universidade Federal do Pampa, 2011. 182 p.

ZANINI, T. V. Enoturismo no Brasil: um estudo comparativo entre as regiões vinícolas do vale dos vinhedos (RS) e do Vale do São Francisco (BA/PE). 2007. 112 p. Dissertação (Mestrado em Turismo) - Universidade de Caxias do Sul, Caxias do SulRS, 2007.

Recebido em: 15-05-2014.

Aprovado em: 13-06-2014. 